\section{Prevalence and determining factors of gastrointestinal parasite infection in pet dogs in an urban area}

\author{
Prevalência e fatores determinantes da infecção por parasitas \\ gastrointestinal em cães em uma área urbana
}

Lyssette Loyola-Suárez', Adrián Guzmán-Sánchez², Norma Angélica Serrano-Aguilar, Silvia Guadalupe Estrada-Barrón ${ }^{4}$, Ana María Rosales-Torres² \& José Antonio Herrera-Barragán²*

'Veterinarian, Student. Universidad Autónoma Metropolitana - UAM, Coyoacán, Ciudad de México, México

Veterinarian, MSc, PhD, Professor. Departamento de Producción Agrícola y Animal, Universidad Autónoma Metropolitana UAM, Coyoacán, Ciudad de México, México

${ }^{3}$ Veterinarian, Specialist, Professor. Policlínica-Veterinaria, Universidad Autónoma Metropolitana - UAM, Tlahuac, Ciudad de México, México

${ }^{4}$ Chemical, MSc, Professor. Policlínica-Veterinaria, Universidad Autónoma Metropolitana - UAM, Tlahuac, Ciudad de México, México

\begin{abstract}
The aim of present study was to evaluate the prevalence of gastrointestinal parasite infection and related factors that govern prevalence in pet dogs. Of 200 fecal samples screened, a prevalence of $39 \%$ was observed, in which Toxocara canis (37\%) and coccidian (29\%) were predominant. Factors that could be associated with an increase in the probability of parasite detection in fecal samples included time since the last deworming, sex, and breed. Pet dogs with > 6 months since the last deworming had a 1.5 times higher probability $(\mathrm{P}<0.05)$ of gastrointestinal parasite infection, whereas purebred and males tended to have $(\mathrm{P}<0.10) 0.9$ and 0.8 times higher probability of gastrointestinal parasite infection than crossbreed and female dogs, respectively. In conclusion, results suggested that animals with > 6 months since last deworming, purebred, and male dogs exhibited a comparatively higher prevalence and probability of gastrointestinal parasite infection.
\end{abstract}

Keywords: breed, dogs, sex, deworming, gastrointestinal parasites.

\section{Resumo}

O objetivo do presente estudo foi avaliar a prevalência de infecção gastrointestinal parasita e fatores relacionados que atuam na prevalência em cães de estimação. De 200 amostras fecais selecionadas, foi observada uma prevalência de 39\%, na qual Toxocara canis (37\%) e coccídeos (29\%) foram predominantes. Fatores que poderiam estar associados com um aumento da probabilidade de detecção do parasita em amostras fecais, incluindo o tempo desde a última desparasitação, sexo e raça. Cães com mais de seis meses desde a última desparasitação tiveram um 1,5 vezes maior a probabilidade $(\mathrm{P}<0,05)$ de infecção por parasitas gastrointestinais que cães de raça pura e machos que tendem a ter 0.9 e 0.8 vezes mais probabilidade de infecção com parasitas gastrointestinais (valor $\mathrm{P}<0,10$ ) que cães mestiços e femeas, respectivamente. Em conclusão, os resultados sugerem que cães com mais de seis meses desde a última desparasitação, de raça pura e masculinos exibiram comparativamente maior prevalência e a probabilidade de infecção gastrointestinal por parasitas.

Palavras-chave: raça, cães, desparasitação, parasitas gastrointestinais.

\section{Introduction}

Parasites (primarily helminthes and protozoan) are the most common microorganisms causing gastrointestinal diseases in dogs (Rodríguez et al., 2001). These parasites induce anorexia, dull coat, vomit, diarrhea, inflammation, and bleeding of the intestinal mucosa, leading to anemia, and may even cause death (Martínez et al., 2008). Moreover, some dog parasites also possess significant zoonotic potential and, thus, may also affect human health (Neves et al., 2014). For example, Toxocara canis causes visceral larva migrans, and ocular larva migrans and covert toxocariasis (Fan et al., 2013), whereas Ancylostoma braziliense, A. caninum and Uncinaria stenocephala cause

\section{BJ $\mathrm{M}$ \\ Brazilian Journal of Veterinary Medicine}

p-ISSN 0100-2430

How to cite: Loyola-Suárez, L., Guzmán-Sánchez, A., Serrano-Aguilar, N.A., Estrada-Barrón, S.G. Rosales-Torres, A.M. \& Herrera-Barragán, J.A. (2019). Prevalence and determining factors of gastrointestinal parasite infection in pet dogs in an urban area. Brazilian Journal of Veterinary Medicine, 41, e100119. http://dx.doi.org/10.29374/25272179.bjvm100119

Financial support: Universidad Autónoma Metropolitana-Unidad Xochimilco.

Conflict of interests: No conflict of interests declared concerning the publication of this article.

Received: September 29, 2018

Accepted: November 19, 2018.

The study was carried out at PoliclínicaVeterinaria, Departamento de Producción Agrícola y Animal de la Universidad Autónoma Metropolitana - UAM, Ciudad de México, México.

\section{*Correspondence}

José Antonio Herrera Barragán

Departamento de Producción Agrícola

y Animal, Universidad Autónoma

Metropolitana-Xochimilco - UAM

CP: 04960 - Ciudad de México, México

E-mail:jherrerab@correo.xoc.uam.mx 
cutaneous larva migrans syndrome (Hendrix et al., 1996). For these reasons, it is important to implement preventive sanitary measures to avoid the transmission of canine parasites to humans.

Several studies investigating the prevalence of gastrointestinal parasite infection in dogs have been performed (Fernández \& Cantó, 2002; Martínez et al., 2008; Romero et al., 2009; Encalada et al., 2011); however, factors governing the prevalence of parasite infection have not been evaluated. Thus, the aim of the present study was to evaluate the prevalence of gastrointestinal parasite infection and the factors governing this prevalence in pet dogs.

\section{Material and methods}

During a six-month period, a total of 200 fecal samples from canines brought to the veterinary clinic for consultation at the Universidad Autónoma Metropolitana-Xochimilco (Mexico City, Mexico) were examined. Fecal samples were collected directly from the rectum using a rectal spoon or clinical thermometer, and processed on the same day of collection according to animal welfare care protocols (Anim.023.18).

All fecal samples were examined using the direct and flotation method. For the direct method, $3 \mathrm{~g}$ of feces was dissolved in formaldehyde (10\%), and a slide with $10 \mathrm{~L}$ of sample dissolved in iodine was prepared. For the flotation method, another $3 \mathrm{~g}$ of feces was dissolved in a saturated sodium chloride solution (33\%), and another slide was prepared (Soulsby 1982). Both slides were observed under an optical microscope using a 40× objective lens. Animals were considered to be positive when eggs of helminthes or protozoan were detected in the fecal samples. The age, breed, sex, and time since the last deworming of the dog were obtained from each owner and registered.

\section{Statistical analysis}

Comparisons of time since deworming, breed, sex. and age were performed using the chi-squared test, with $\mathrm{P}<0.05$ considered to be statistically significant, or $\mathrm{P}<0.10$ for tendencies . The results are expressed as frequency and prevalence with corresponding 95\% confidence interval (CI). The effects of time since last deworming, breed, sex, and age on the incidence of gastrointestinal parasite infection were analyzed using logistic regression and odds ratios were calculated. All analyses were performed using JMP 13 (SAS Institute, USA).

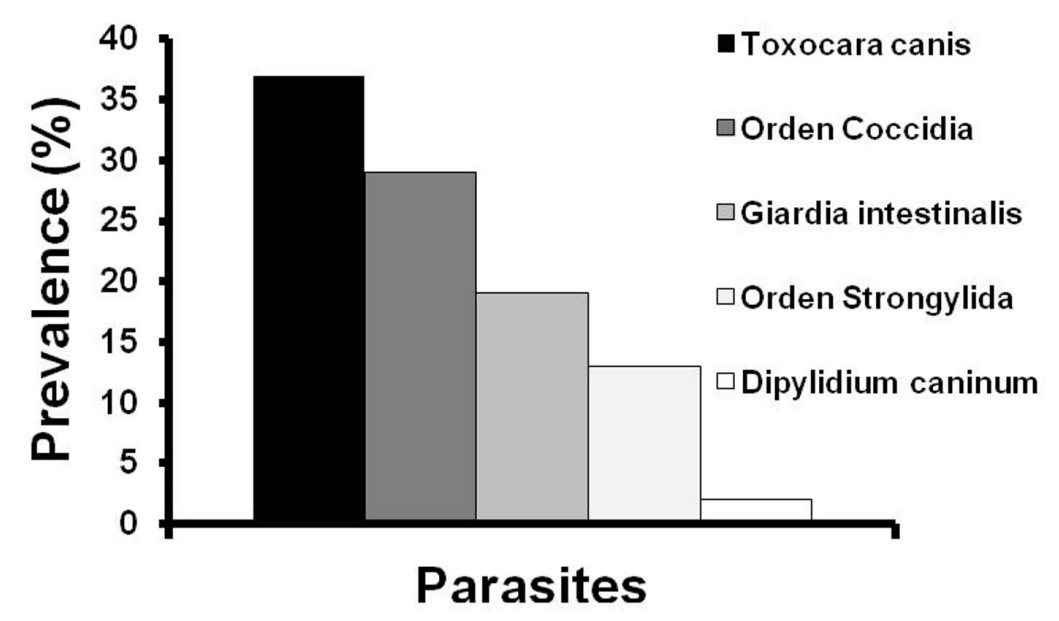

Figure 1. Prevalence of gastrointestinal parasites in owned dogs from urban area. 
Table 1. Prevalence of gastrointestinal parasites according to deworming time, breed, sex and age in dogs.

\begin{tabular}{|c|c|c|c|c|}
\hline & Total & Frequency & $\begin{array}{c}\text { Prevalence } \\
(95 \% \text { CI })\end{array}$ & Pvalue \\
\hline Total & 200 & 78 & $39(32-46)$ & \\
\hline \multicolumn{5}{|c|}{ Last deworming } \\
\hline$<6$ month & 115 & 55 & $48(39-57)$ & 0.003 \\
\hline$>6$ month & 85 & 23 & $27(16-37)$ & \\
\hline \multicolumn{5}{|l|}{ Breed } \\
\hline Purebred & 150 & 64 & $43(34-50)$ & 0.066 \\
\hline Crossbred & 50 & 14 & $28(15-40)$ & \\
\hline \multicolumn{5}{|l|}{ Sex } \\
\hline Females & 92 & 29 & $32(21-41)$ & 0.046 \\
\hline Males & 108 & 49 & $45(35-55)$ & \\
\hline \multicolumn{5}{|l|}{ Age } \\
\hline$<6$ month & 47 & 21 & $45(30-59)$ & 0.516 \\
\hline 6-12 month & 17 & 5 & $29(5-53)$ & \\
\hline$>12$ month & 136 & 52 & $38(30-46)$ & \\
\hline
\end{tabular}

\section{Results}

\section{Gastrointestinal parasite detection}

Seventy eight of 200 (39\%; 95\% CI 32-46\%) animals were positive for gastrointestinal parasites (Table 1). Toxocara canis exhibited the highest prevalence (37\%), followed by coccidian oocysts (29\%). Other gastrointestinal parasites included Giardia intestinalis, hookworms, and Dipylidium caninum (Figure 1).

Table 2. Risk factors for presence of gastrointestinal parasites in owned dogs from urban area.

\begin{tabular}{ccccc}
\hline & Risk Factors & Odd Ratio & IC al 95\% & P value \\
\hline Deworming time & $<6$ month & 1 & & \\
& $>6$ month & 2.5 & $1.4-4.6$ & 0.003 \\
Crossbred & 1 & & \\
Pureed & Females & 1.9 & $0.9-4.0$ & 0.067 \\
Sex & Males & 1 & & \\
Age & $<6$ month & 1.8 & $0.9-3.2$ & 0.055 \\
& $6-12$ month & 0.5 & $0.1-2.0$ & 0.34 \\
& $>12$ month & 1.1 & $0.4-2.8$ & 0.85 \\
\hline
\end{tabular}

The prevalence of gastrointestinal parasites was higher $(\mathrm{P}<0.05)$ in males and in animals with last deworming > 6 months (Table 1). Similarly, regression logistic analysis revealed that dogs dewormed $>6$ months and males had higher probability $(\mathrm{P}<0.05)$ of parasite infection (Table 2 ). With regard to breed and sex, purebred dogs and male dogs tended to have a higher prevalence of parasites $(\mathrm{P}<0.10)$, and almost 100\% higher probability of parasite occurrence than crossbred 
dogs and females, respectively (Tables 1 and 2). Finally, the different ranges of age examined in the present study did not affect $(\mathrm{P}>0.10)$ either prevalence or probability of gastrointestinal parasite infection (Tables 1 and 2).

\section{Discussion}

Results of the present study revealed that time since last deworming, sex, and breed are factors that may be associated with gastrointestinal parasite infection in pet dogs.

In dogs with > 6 months since last deworming, the prevalence of gastrointestinal parasites was $77 \%$ higher and the odds ratios for parasite infection was 2.5 times higher compared with dogs that were dewormed < 6 months. Our results agree with those reported by Martínez-Barbabosa et al. (2011), who reported an increase in the prevalence of gastrointestinal parasites with increases in time since the last deworming. Palmer et al. (2010), reported that 85\% of veterinaries recommended prophylactic deworming every 3 months as a good strategy for gastrointestinal parasite control. This recommendation is supported by evidence showing that the prevalence of helminthes increases 3 months after deworming (Sager et al., 2006). Based on our results and other similar reports in the literature, we suggest that deworming treatment should not exceed 6 months. This strategy may reduce the prevalence of gastrointestinal parasites in pet dogs and, thus, the probability of human infection.

In the present study, purebred dogs had a higher prevalence, and the odds of gastrointestinal parasite infection was higher compared with crossbred dogs. The effect of breed (purebred versus crossbred) on the prevalence of gastrointestinal parasites in dogs was evaluated previously and the results were contradictory. Mirzaei \& Fooladi (2013) and Neves et al. (2014), did not find differences in the prevalence of gastrointestinal parasites between purebred and crossbred dogs, whereas our results agree with those of Llanos et al. (2010), who also reported a higher percentage of positive cases to gastrointestinal parasites in purebred dogs compared with crossbred animals. Moreover, purebred dogs are more susceptible to Toxocara canis (Quijada et al., 2008). Based on these results, it is likely that crossbred dogs have more resistance to parasites and, thus, lower prevalence and probability of infection.

With respect to sex, males had a higher prevalence and probability (odds 1.8) of gastrointestinal parasite infection than females. These results were in agreement with those reported by Sarmiento et al. (2009). However, some studies have reported that females are more susceptible to gastrointestinal parasites than males (Neves et al., 2014) or, in other cases, there was no sex effect on the prevalence of gastrointestinal parasites (Mirzaei \& Fooladi, 2013).

The prevalence of gastrointestinal parasites has been evaluated worldwide using a coproscopy assay. In the present study, the prevalence of gastrointestinal parasites was 39\%, which was higher than the prevalence reported in Colombia (22.2\%) (Giraldo et al., 2005) but lower than those reported in Venezuela 58\% (Quijada et al., 2008); and Chile 63\% (López et al., 2006). These differences may be associated with different climatic conditions where each experiment was performed.

The parasites most frequently found were Toxocara canis (37\%) and Coccidia (26\%). The findings are consistent with those reported previously (Gorman et al., 2006). The presence of Toxocara canis may be due to biological factors associated with parasites, or hygiene and management of the owners. For example, Toxocara canis eggs have a very thick cover that provide superior resistance (Cuenca et al., 2012) by which these helminthes can remain viable up for to 5 years, and may spread on the ground and in pastures (Martínez et al. 2008).

In conclusion, the results of this study demonstrated that Toxocara canis was the most common parasite detected in fecal samples from pet dogs, and that animals dewormed $>6$ months, purebred, and male were more susceptible to gastrointestinal parasite infection. Based on these results, we recommend that deworming should be performed at least every 6 months, especially in purebred and male dogs.

\section{References}

Cuenca, C. J., Morales, M. A., Molina, L. E., Cepero, R. O., Gutiérrez, A. D., \& Fernández, P. J. (2012). Prevalence and factors that favor of presentation of toxocara canis and ancylostoma caninum in companion dogs. Revista Electrónica de Veterinaria, 13, 1-15. 
Encalada, M. L., Ubaldo, D., Vargas, M. J., García-Ramírez M. J., \& Medina-Hernández, R. E. (2011). Prevalencia de parásitos gastroentéricos de canidos en la ciudad de Escárcega, Campeche, México. Euciencia, 27, 209-217.

Fan, C. K., Liao, C. W., \& Cheng, Y.C. (2013). Factors affecting disease manifestation of toxocarosis in humans: genetics and environment. Veterinary Parasitology,193(4), 342-352. http://dx.doi.org/10.1016/j.vetpar.2012.12.030. PMid:23290279.

Fernández, C. F., \& Cantó, A. G. (2002). Frecuencia de helmintos en intestinos de perros sin dueño sacrificados en la ciudad de Querétaro, México. Veterinaria, 33, 247-253.

Giraldo, I. M., García, L. N., \& Castaño, C. J. (2005). Prevalencia de Helmintos Intestinales en Caninos del Departamento del Quindío. Biomédica, 25(3), 346-352. http://dx.doi.org/10.7705/biomedica.v25i3.1359. PMid:16276682.

Gorman, T., Soto, A., \& Alcaino, H. (2006). Gastrointestinal parasitism in dogs from municipalities of different socioeconomical status from Santiago. Parasitología Latinoamericana, 61, 126-132.

Hendrix, C. M., Bruce, H. S., Kellman, N. J., Harrelson, G., \& Bruhn, B. F. (1996). Cutaneous larva migrans and enteric hookworm infections. Journal of the American Veterinary Medical Association, 209(10), 1763-1767. PMid:8921039.

Llanos, M., Condori, M., Teddy, I., \& Loza, M. M. (2010). Enteric Parasitic in canines (Canis familiaris) in the urban area of Coroico, Nor Yungas department of La Paz Bolivia. Journal of the Selva Andina Research Society, 1, 37-39.

López, D. J., Abarca, V. K., Paredes, M. P., \& Inzunza, T. E. (2006). Intestinal parasites in dogs and cats with gastrointestinal symptoms in Santiago, Chile. Revista Medica de Chile, 134(2), 193-200. PMid:16554927.

Martínez, B. I., Gutiérrez, C. E., Alpízar, S. E., \& Pimienta, L. R. (2008). Parasitic contamination by dog feces collected from the streets of San Cristobal de Las Casas, Chiapas, Mexico. Veterinaria, 39, 173-180.

Martínez-Barbabosa, I., Gutiérrez-Cárdenas, L. M., Aguilar-Venegas, J., Pimienta-Lastra, R. J., \& Shea, M. (2011) Frequency of geohelminths in pet dogs from seven municipalities of Mexico City. Veterinaria, 42, 83-91.

Mirzaei, M., \& Fooladi, M. (2013). Coproscopy survey of gastrointestinal parasites in owned dogs of Kerman city, Iran. Veterinaria Italiana, 49(3), 309-313. PMid:24166482.

Neves, D., Lobo, L., Simões, P. B., \& Cardoso, L. (2014). Frequency of intestinal parasites in pet dogs from an urban area (Greater Oporto, northern Portugal). Veterinary Parasitology, 200(3-4), 295-298. http://dx.doi.org/10.1016/j. vetpar.2013.11.005. PMid:24433853.

Palmer, C. S., Robertson, I. D., Traub, R. J., Rees, R., \& Thompson, R. C. (2010). Intestinal parasites of dogs and cats in Australia: the veterinarian's perspective and pet owner awareness. Veterinary Journal, 183(3), 358-361. http://dx.doi.org/10.1016/j.tvjl.2008.12.007. PMid:19196527.

Quijada, J., Betancourt, A., Pérez, A., Vivas, I., Aguirre, J., \& Reyes, Y. (2008). Canine gastrointestinal parasites in a canine kennel in Venezuela. Revista de la Facultad de Ciencias Veterinarias. Universidad Central de Venezuela, 49, 91-98.

Rodríguez, V. R., Cob, G. L., \& Domínguez, A. J. (2001). Frecuencia de parásitos gastrointestinales en animales domésticos diagnosticados en Yucatán, México. Revista Bioética, 12, $19-25$.

Romero, N. C., García, C. A., Mendoza, M. G., Torres, C. N., \& Ramírez, R. N. (2009). Contaminación por Toxocara spp. En parques de Tulyehualco, México. Revista de la Facultad de Ciencias Veterinarias. Universidad Central de Venezuela, 19, 253-256.

Sager, H., Moret, CH. S., Grimm, F., Deplazes, P., Doherr, M. G., \& Gottstein, B. (2006). Coprological study on intestinal helminths in Swiss dogs: temporal aspects of anthelminthic treatment. Parasitology Research, 98(4), 333-338. http://dx.doi.org/10.1007/s00436-005-0093-8. PMid:16374614.

Sarmiento, M. E., Andrade, J. A., \& Giraldo, C. J. (2009). Prevalence of Toxocara canis and other gastrointestinal parasites in street map dogs from Sogamoso. Ciencia Agricola, 7, 55-62.

Soulsby, E. J. L. (1982) Helminths, arthropods and protozoa of domesticated animals. London: Baillere Tindall. 